\title{
Gute Frage - gute Antwort
}

\section{Welchen Patienten können Sie nicht vergessen?}

\begin{abstract}
W ie viele Patienten haben Sie tagtäglich auf Ihrem Behandlungsstuhl sitzen? Und wie viele macht das dann auf die Woche, den Monat, das Jahr hochgerechnet? Sicherlich eine beachtliche Zahl. Und da ist es Ihnen nicht im Geringsten zu verübeln, wenn Sie sich nicht mehr an jedes einzelne Gesicht erinnern können. Doch sicher gibt es bei Ihnen auch den einen Patienten, der in Ihrer Erinnerung fest verankert ist. Warum ihnen welcher Patient immer noch präsent ist, verraten uns dieses Mal die befragten Kollegen.
\end{abstract}

Dr. Linda Franck // Dresden

Im Notdienst kam eine aufgeregte Mutter mit ihrem acht Monate alten Baby zur mir, das auf die Fliesen gestürtzt war. Der gerade $1 \mathrm{~mm}$ durchgebrochene Milchfrontzahn war stark disloziert, die Schleimhaut war eingerissen und blutete. Ich setzte die Zange an und zog den Zahn ohne zu zögern. Das Baby hat sich glücklicherweise kaum beschwert. Mutter und Baby kommen seitdem regelmäßig zur Kontrolle und sind immer noch glücklich, dass dieser erste ungeplante Zahnarztbesuch doch so gut über die Bühne ging.
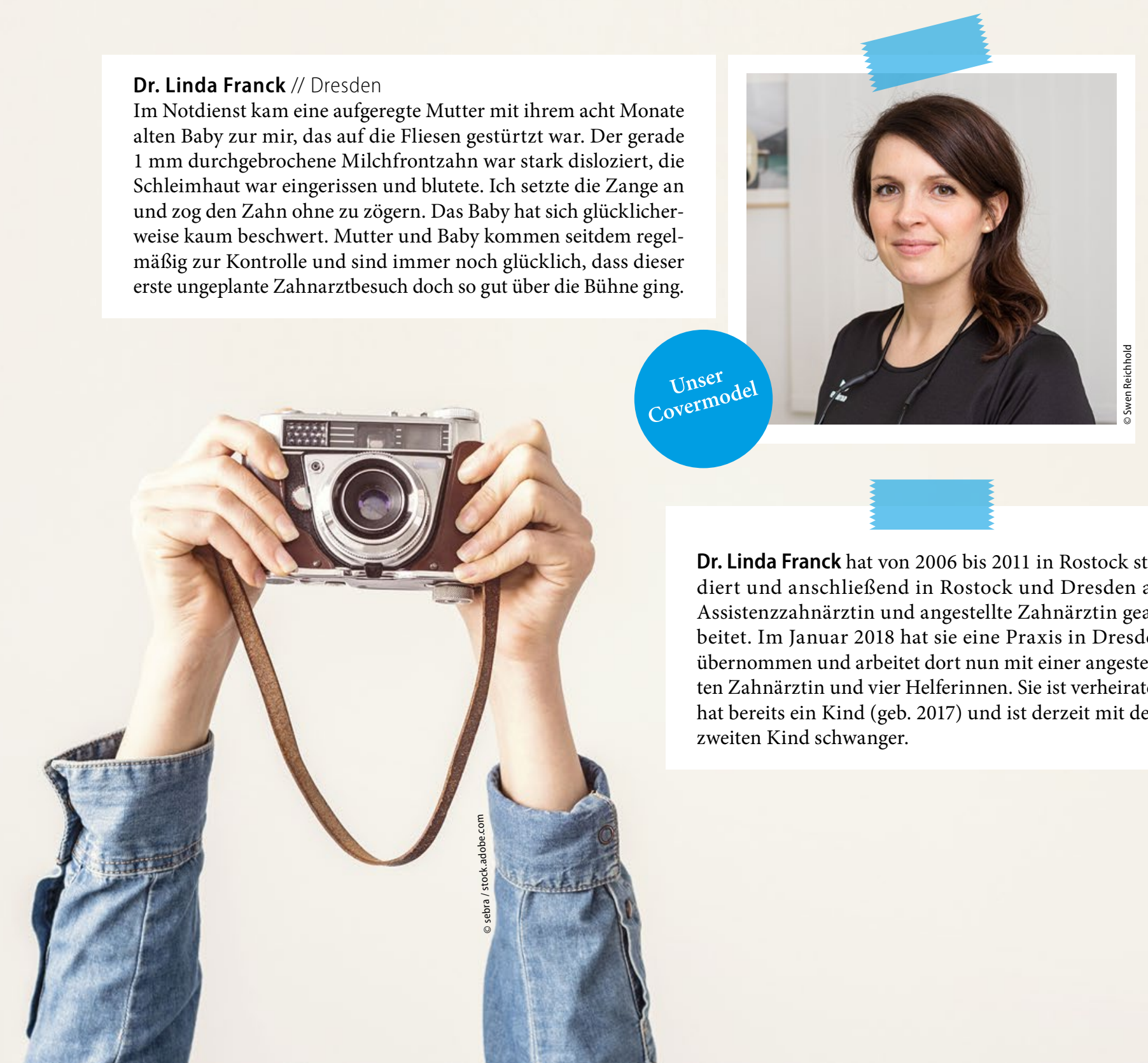

Dr. Linda Franck hat von 2006 bis 2011 in Rostock studiert und anschließend in Rostock und Dresden als Assistenzzahnärztin und angestellte Zahnärztin gearbeitet. Im Januar 2018 hat sie eine Praxis in Dresden übernommen und arbeitet dort nun mit einer angestellten Zahnärztin und vier Helferinnen. Sie ist verheiratet, hat bereits ein Kind (geb. 2017) und ist derzeit mit dem zweiten Kind schwanger. 


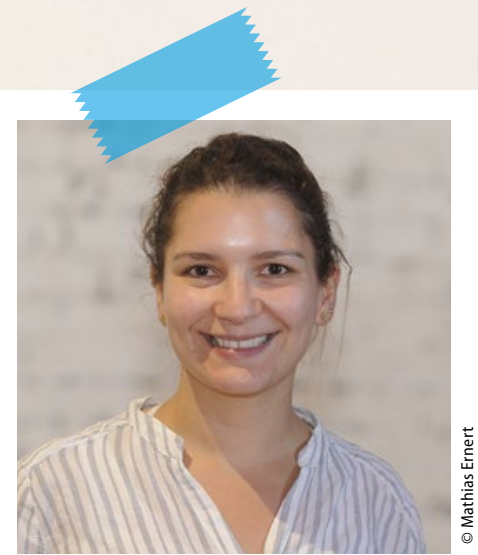

Mariem Youssef // Frankfurt am Main Ich kann einen Patienten nicht vergessen, der wegen Zahnfleischbluten einen Krankenwagen gerufen hat!

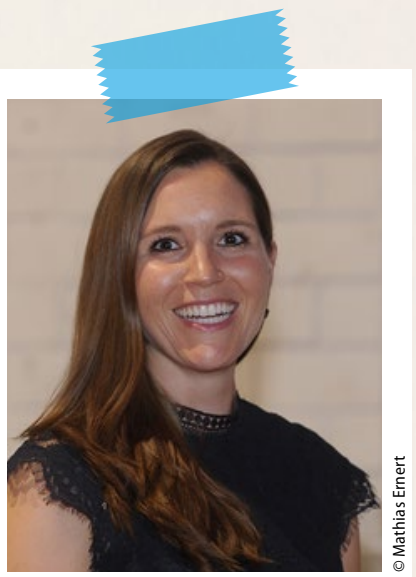

Dr. Verena Freier // Bad Soden

Wahrscheinlich ist das der erste Patient in meiner eigenen Praxis, ich weiß noch genau, wer das war.

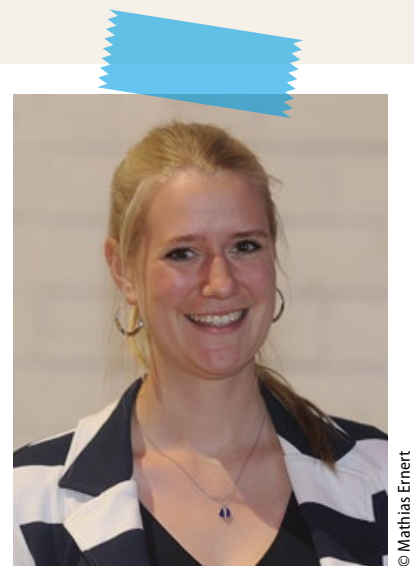

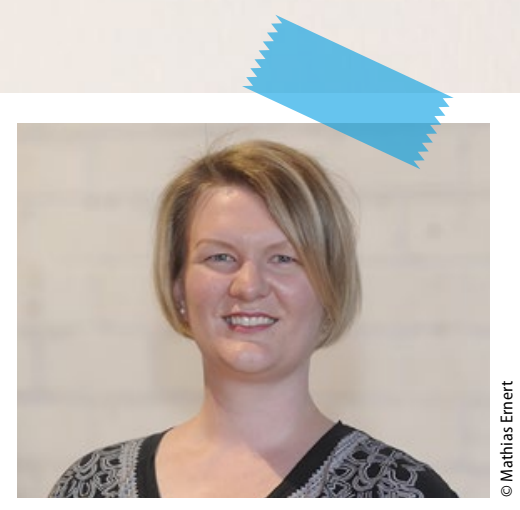

Dr. Annika Wälter // Obernburg

Ich hatte mal einen Patienten, den musste ich erst einmal davon überzeugen, dass ich die richtige Behandlerin für ihn bin. Er saß mit verschränkten Armen vor mir und zeterte erst einmal los, was er will und was er nicht will. Mit der Zeit haben wir uns gut angefreundet und er ist jetzt sehr zufrieden.

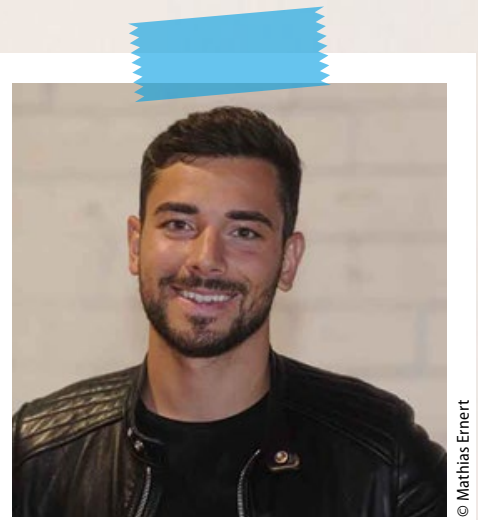

Ludwig Malerowitz // Berlin

Mir bleibt eine 28-jährige Frau in Erinnerung, die keine Zähne mehr hatte, und das schon seit sechs Jahren. Da musste ich eine komplette Sanierung machen.

\section{Antonia Völlings // Erlangen}

In der Prothetik hatte ich einen Patienten, der lebte im Altenheim. Im Winter war er gestürzt, blutete daraufhin und hatte ein blaues Auge. Trotzdem ist er zunächst zu mir in die Behandlung gekommen, worauf ich ihn erst mal ins Krankenhaus schicken musste. Aber es war ihm so wichtig, dass ich ihn behandeln kann, weil er ja wusste, dass wir immer Patienten suchen. 